\title{
Asymmetric Reduction of Poly(isopropenyl methyl ketone) via Rhodium(I)-Catalyzed Hydrosilylation
}

\author{
Michio KAWAI and Toshio MASUdA \\ Department of Polymer Chemistry, Kyoto University, \\ Yoshida, Sakyo-ku, Kyoto 606, Japan.
}

(Received November 6, 1980)

\begin{abstract}
The asymmetric reduction of poly(isopropenyl methyl ketone ) via hydrosilylation gave a new optically active polymer, poly(3-methyl-3-buten-2-ol). The hydrosilylation was carried out with diphenylsilane and a rhodium(I) catalyst containing a chiral phosphine ligand. The effects of the reaction conditions on the optical rotation of the polymer formed were studied in detail. The highest specific rotation $\left([\alpha]_{D}^{20}\right)$ reached was $+18.4^{\circ}$, and was attained by the hydrosilylation in 1,4-dioxane at $30^{\circ} \mathrm{C}$. On the other hand, both pinacolone (as a monomeric ketone) and a $1: 1$ copolymer of isopropenyl methyl ketone with styrene produced the corresponding alcohols having negative small rotations $\left(c a .-3^{\circ}\right)$.
\end{abstract}

KEY WORDS Asymmetric Reduction / Hydrosilylation / Rhodium Complex / Polymer Reaction / Poly(isopropenyl methyl ketone) / Poly(3methyl-3-buten-2-ol) / Optically Active Polymer /

Synthetic optically active polymers are important from the viewpoint of the possibility of applying them to biomimetic polymers, polymer reagents or catalysts for asymmetric reactions, asymmetricselective column materials, and so on. Though extensively investigated, asymmetric-selective polymerization rarely affords highly optically active polymers. ${ }^{1}$ On the other hand, as highlighted in the asymmetric synthesis of amino acids, transitionmetal catalyzed asymmetric reactions have made remarkable progress in recent years. ${ }^{2-4}$ Therefore, transition-metal catalyzed asymmetric reactions of polymers seem to provide a feasible method for synthesizing highly optically active polymers.

We have reported the asymmetric reduction of poly(methyl vinyl ketone) to poly(3-buten-2-ol) via hydrosilylation. ${ }^{5}$ Hydrosilylation was performed using either diphenylsilane or $\alpha$-naphthylphenylsilane, and was catalyzed by a mixture of $\mu$ dichlorotetracyclooctenedirhodium(I) and (-)-2,3$O$-isopropylidene-2,3-dihydroxy-1,4-bis(diphenylphosphino)butane [(-)-DIOP]. The highest optical rotation $\left(\left[\alpha_{\mathrm{D}}^{20}\right]\right)$ of poly (3-buten-2-ol) reached $+68^{\circ}$. Further, the direct synthesis of optically active poly(3-buten-2-ol) from methyl vinyl ketone was achieved by conducting polymerization and hydrosilylation successively in one pot. ${ }^{6}$

In the present investigation, the asymmetric reduction of homo- and co-polymers of isopropenyl methyl ketone via hydrosilylation was carried out (see eq 1). The purposes of the present study are to

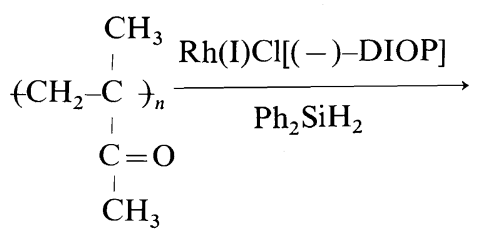<smiles>CC(C)[C@H](C)[C@H](C)O</smiles> 
synthesize a new optically active polymer and to elucidate the effects of $\alpha$-methyl group, reaction conditions, and comonomer (styrene) unit on the asymmetric reaction.

\section{EXPERIMENTAL}

\section{Materials}

Isopropenyl methyl ketone was prepared by the literature method. ${ }^{7}$ Yield $45 \%$, bp $96.5^{\circ} \mathrm{C}$ (lit. yield $58 \%$, bp $\left.96-97^{\circ} \mathrm{C}^{7}\right)$. $\mu$-Dichlorotetracyclooctenedirhodium(I), ${ }^{8}(-)$-DIOP $^{9}$ and diphenylsilane ${ }^{10}$ were also prepared as described in the literature.

Poly(isopropenyl methyl ketone) was obtained by the polymerization in tetrahydrofuran at $60^{\circ} \mathrm{C}$ for $48 \mathrm{~h}$ catalyzed by azobisisobutyronitrile (AIBN); $[\mathrm{M}]_{0}=5.0 \mathrm{~mol} \mathrm{dm}^{-3}, \quad[\mathrm{AIBN}]=0.20 \mathrm{~mol} \mathrm{dm}^{-3}$. Polymer yield $91 \%$. The copolymers of either isopropenyl methyl ketone or methyl vinyl ketone with styrene were synthesized under conditions similar to those for poly(isopropenyl methyl ketone); feed monomer ratios 1.0. The monomer conversions in the copolymerizations were practically quantitative.

\section{Procedures}

A typical procedure for the asymmetric reduction of poly(isopropenyl methyl ketone) is as follows: A mixture of $\mu$-dichlorotetracyclooctenedirhodium(I) $(35.9 \mathrm{mg}, \quad 0.050 \mathrm{mmol}),(-)-\mathrm{DIOP} \quad(50.0 \mathrm{mg}$, $0.10 \mathrm{mmol})$, and tetrahydrofuran $\left(5 \mathrm{~cm}^{3}\right)$ was aged at $50^{\circ} \mathrm{C}$ for $30 \mathrm{~min}$ under nitrogen. Then the catalyst solution was added to a mixture of poly(isopropenyl methyl ketone) $(0.841 \mathrm{~g}, 10 \mathrm{mmol})$, diphenylsilane $(2.76 \mathrm{~g}, 15 \mathrm{mmol})$, and tetrahydrofuran $\left(11.4 \mathrm{~cm}^{3}\right)$. The reaction was continued at $50^{\circ} \mathrm{C}$ for 3 days under nitrogen (total reaction volume $20 \mathrm{~cm}^{3}$ ). The hydrolysis of the silyl ether produced was carried out as described before. ${ }^{6}$

Conversions for hydrosilylation were approximately determined by using two key bands (2960 and $1700 \mathrm{~cm}^{-1}$ ) in the IR spectra, whereas subsequent hydrolysis was always quantitative.

The hydrosilylation of monomeric ketones was conducted under the same conditions as those for polymeric ketones. Following the reaction, tetrahydrofuran (solvent) was replaced by acetone and the hydrosilylation product was hydrolyzed with $1 \mathrm{~N}$ hydrochloric acid $\left(4 \mathrm{~cm}^{3}\right)$ at room temperature for $1 \mathrm{~h}$, and the organic layer was extracted with ether $\left(30 \mathrm{~cm}^{3}\right)$. The product was isolated by fractional distillation.

The IR and ${ }^{1} \mathrm{H}$ NMR spectra of the polymers were recorded on a Shimadzu IR $27 \mathrm{G}$ spectrophotometer $(\mathrm{KBr}$ disc) and a Varian HA-100 spectrometer $\left(\mathrm{CDCl}_{3}\right.$ soln $)$, respectively. The optical rotations were measured on a JASCO J-20 spectropolarimeter (ethanol soln; concn $10.0 \mathrm{~g} \mathrm{dm}^{-3}$ ).

\section{RESULTS AND DISCUSSION}

\section{Characterization of the Asymmetric-Reduction} Product from Poly(isopropenyl methyl ketone)

The hydrosilylation of poly(isopropenyl methyl ketone) quantitatively proceeded under the following conditions: $[\mathrm{C}=\mathrm{O}]=0.50 \mathrm{~mol} \mathrm{dm}^{-3},[\mathrm{C}=\mathrm{O}] /$ $[\mathrm{Rh}]=100, \quad[\mathrm{Si}] /[\mathrm{C}=\mathrm{O}]=1.5, \quad[(-)-\mathrm{DIOP}] /[\mathrm{Rh}]=$ 1.00 in tetrahydrofuran at $50^{\circ} \mathrm{C}$ for 3 days. The reaction of poly(methyl vinyl ketone) is complete within 1 day under the same conditions ${ }^{6}$; thus poly(isopropenyl methyl ketone) is less reactive than poly(methyl vinyl ketone) owing to steric effects. The silyl ether formed from poly(isopropenyl methyl ketone) was quantitatively hydrolyzed by treatment with $1 N$ hydrochloric acid at room temperature for $1 \mathrm{~h}$.

The IR spectrum of the hydrolysis product consisted of the following absorptions: $3420(\mathrm{~s})$, $2975(\mathrm{~s}), 1460(\mathrm{~m}), 1370(\mathrm{~m}), 1060(\mathrm{~s}), 950(\mathrm{w})$, and $890(\mathrm{w}) \mathrm{cm}^{-1}$. The absorptions at 3420 and $1060 \mathrm{~cm}^{-1}$ in the product are due to $\mathrm{O}-\mathrm{H}$ and $\mathrm{C}-\mathrm{O}$ stretchings, respectively; no bands due to the carbonyl group $\left(1700 \mathrm{~cm}^{-1}\right)$ and the $\mathrm{Si}-\mathrm{H}$ bond $\left(2150 \mathrm{~cm}^{-1}\right)$ were observed. Figure 1 shows the ${ }^{1} \mathrm{H}$

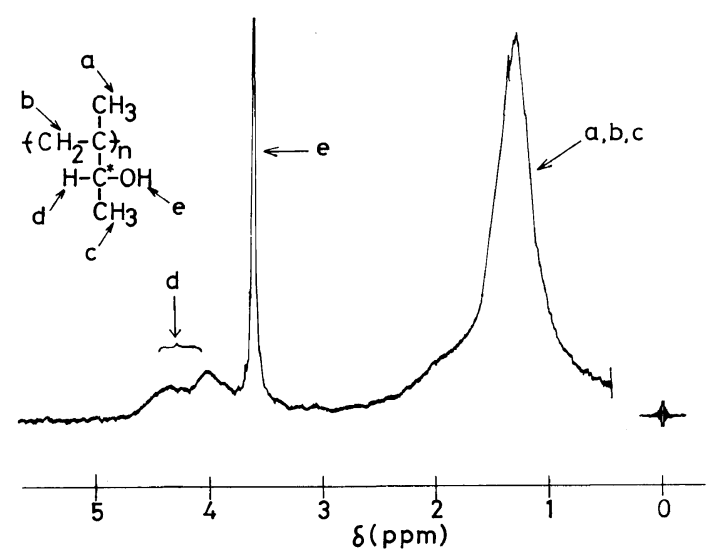

Figure 1. ${ }^{1} \mathrm{H}$ NMR spectrum of poly(3-methyl-3buten-2-ol). 
NMR spectrum of the hydrolysis product along with the assignment of each peak. Neither the sharp acetyl protons of poly(isopropenyl methyl ketone) $(\delta 1.9 \mathrm{ppm})$ nor the aromatic protons of the diphenylsilyl group $(\delta 7-8 \mathrm{ppm})$ could be found. Thus both spectra indicate that the polymer produced was composed only of the poly(3-methyl-3-buten-2ol) structure.

Poly(3-methyl-3-buten-2-ol) obtained in the present study is a new polymer. It would be impossible to obtain this polymer directly through any polymerization, since the corresponding monomer has a hydroxyl group and no resonance-stabilizing groups. Poly(3-methyl-3-buten-2-ol) had the form of white powder, and showed a softening point of $183-187^{\circ} \mathrm{C}$. The polymer was soluble in alcohols, tetrahydrofuran, 1,4-dioxane and dimethyl sulfoxide, whereas benzene, ethylene dichloride and water behaved as nonsolvents; generally poly(3methyl-3-buten-2-ol) was soluble in more polar solvents than was poly(isopropenyl methyl ketone).

\section{Effects of Reaction Conditions on Optical Rotation}

The effects of solvents on hydrosilylation were examined. The reaction quantitatively occurred not only in ethers (tetrahydrofuran, 1,4-dioxane, 1,2-

Table I. Asymmetric reduction of poly(isopropenyl methyl ketone) via hydrosilylation in various solvents $^{\mathrm{a}}$

\begin{tabular}{|c|c|c|c|}
\hline No. & Solvent & $\frac{\text { Conversion }}{\%}$ & {$[\alpha]_{\mathrm{D}}^{20} /{ }^{\circ \mathrm{b}}$} \\
\hline 1 & $\mathrm{THF}$ & 100 & +13.8 \\
\hline 2 & 1,4-DOX & 100 & +14.1 \\
\hline 3 & $\left(\mathrm{CH}_{3} \mathrm{OCH}_{2}\right)_{2}$ & 100 & +9.6 \\
\hline 4 & $\left(\mathrm{CH}_{2} \mathrm{Cl}\right)_{2}$ & 100 & +10.2 \\
\hline 5 & $\mathrm{C}_{6} \mathrm{H}_{5} \mathrm{Cl}$ & 100 & +13.2 \\
\hline 6 & $\mathrm{C}_{6} \mathrm{H}_{6}$ & 100 & +10.0 \\
\hline 7 & THF & 25 & +7.0 \\
\hline 8 & THF & 75 & +9.8 \\
\hline $9^{c}$ & THF & 100 & +13.7 \\
\hline
\end{tabular}

${ }^{\text {a }}$ Hydrosilylated at $50^{\circ} \mathrm{C}$ for 3 days; $[\mathrm{C}=\mathrm{O}]=0.50 \mathrm{~mol}$ $\mathrm{dm}^{-3}, \quad[\mathrm{C}=\mathrm{O}] /[\mathrm{Rh}]=100, \quad[(-)-\mathrm{DIOP}] /[\mathrm{Rh}]=1.0$, $\left[\mathrm{Ph}_{2} \mathrm{SiH}_{2}\right] /[\mathrm{C}=\mathrm{O}]=1.5$ (No. 7: 0.25, No. 8: 0.75).

b Specific rotation of poly(3-methyl-3-buten-2-ol) measured in ethanol (concn $10.0 \mathrm{~g} \mathrm{dm}^{-3}$ ) (Nos. 7, 8: in 1,4DOX).

${ }^{\mathrm{c}}$ Hydrosilylated for 7 days. dimethoxyethane) but also in halogenated hydrocarbons (ethylene dichloride, chlorobenzene) and in benzene. Thus, various solvents proved to be useful for the $\mathrm{Rh}(\mathrm{I})$-catalyzed asymmetric hydrosilylation of ketones, although only benzene has been used in the literature. ${ }^{11}$

The specific rotations of polymers, measured in ethanol (concn. $10.0 \mathrm{~g} \mathrm{dm}^{-3}$ ), were around $+10^{\circ}$, and 1,4-dioxane gave the highest value of $+14.4^{\circ}$ (Table I). The change in the rotation with solvents cannot be simply explained, for instance, in terms of solvent polarity.

The optical rotation of the product whose conversion was $25 \%$, was larger than expected, in consideration of its hydroxyl group content (Table I, No. 7). Either of the following seems responsible for this finding: i) the stereospecificity of the reaction decreases with increasing conversion, ii) the presence of appropriate amounts of unreacted acetyl group enhances the rotation. Even though the hydrosilylation reaction was continued longer than necessary for the quantitative conversion, the optical rotation of the product did not reduce (Table I; No. 9); this indicates that no racemization took place during the reaction.

Table II shows the results for hydrosilylations at

Table II. Asymmetric reduction of poly(isopropenyl methyl ketone) via hydrosilylation at different temperatures $^{\mathrm{a}, \mathrm{b}}$

\begin{tabular}{|c|c|c|c|c|}
\hline No. ${ }^{c}$ & Solvent & $\frac{\text { Temp }}{{ }^{\circ} \mathrm{C}}$ & $\frac{\text { Time }}{\text { day }}$ & {$[\alpha]_{\mathrm{D}}^{20} / \mathrm{dd}$} \\
\hline 1 & THF & 50 & 3 & +13.8 \\
\hline 10 & THF & 30 & 7 & +14.4 \\
\hline 11 & 1,4-DOX & 70 & 2 & +7.1 \\
\hline 2 & 1,4-DOX & 50 & 3 & +14.1 \\
\hline 12 & 1,4-DOX & 30 & 7 & +18.4 \\
\hline 13 & $\mathrm{C}_{6} \mathrm{H}_{5} \mathrm{Cl}$ & 70 & 2 & +6.9 \\
\hline 5 & $\mathrm{C}_{6} \mathrm{H}_{5} \mathrm{Cl}$ & 50 & 3 & +13.2 \\
\hline 14 & $\mathrm{C}_{6} \mathrm{H}_{5} \mathrm{Cl}$ & 30 & 7 & +15.3 \\
\hline
\end{tabular}

${ }^{\text {a }}$ Hydrosilylated at $[\mathrm{C}=\mathrm{O}]=0.50 \mathrm{~mol} \mathrm{dm}^{-3},[\mathrm{C}=\mathrm{O}] /$ $[\mathrm{Rh}]=100, \quad[(-)-\mathrm{DIOP}] /[\mathrm{Rh}]=1.0, \quad\left[\mathrm{Ph}_{2} \mathrm{SiH}_{2}\right] /$ $[\mathrm{C}=\mathrm{O}]=1.5$.

b The conversions were over $99 \%$ according to IR spectra.

c Numbers are common to those in Table I.

d Specific rotation of poly(3-methyl-3-buten-2-ol) measured in ethanol (concn $10.0 \mathrm{~g} \mathrm{dm}^{-3}$ ). 
different temperatures. The reaction was faster at higher temperatures, while the optical rotation of the product increased with decreasing temperature for all solvents examined. The highest specific rotation of poly(3-methyl-3-buten-2-ol) observed in the present study reached +18.4 , which was attained by the hydrosilylation in 1,4-dioxane at $30^{\circ} \mathrm{C}$ for 7 days. Although the synthesis of a product having a still higher rotation was attempted by carrying out hydrosilylation in tetrahydrofuran at 0 C for 14 days, the conversion was as low as $54 \%$ and the optical rotation was not determined.

\section{Effects of Measuring Conditions on Optical Rotation}

The high optical rotation of polymer often stems not from a chiral side group itself but from the conformation of main chain [e.g., poly(triphenylmethyl methacrylate), ${ }^{12}$ poly(trans-2-methyl-1,3pentadiene $)^{13}$ ]. Provided that a polymer takes a helical conformation, resulting in high optical rotation, the measuring conditions will have great influence. In order to make clear as to whether this point has any connection with the present study, the rotation was measured under various conditions. It was found that the rotation did not decrease very much even under conditions which destroy hydrogen bonding (Table III, No. 3, 4, 6). This leads to the conclusion that no particular polymer confor- mation contributes to the optical rotation observed.

\section{Asymmetric Reduction of Monomeric Ketones and Copolymers}

The specific rotations up to +18.4 observed in the present investigation are unusually large for aliphatic alcohols. The optical yields, however, could not be evaluated since the rotation of optically pure poly(3-methyl-3-buten-2-ol) is not known.

The optical rotation of the asymmetric-reduction product from poly(methyl vinyl ketone) is larger

Table III. Effect of measuring conditions on the $[\alpha]_{D}$ of poly(3-methyl3-buten-2-ol) ${ }^{\mathrm{a}}$

\begin{tabular}{|c|c|c|c|}
\hline \multirow{2}{*}{ No. } & \multirow{2}{*}{ Solvent } & Temp & {$[\alpha]_{\mathrm{D}}$} \\
\hline & & ${ }^{\circ} \mathrm{C}$ & $\circ$ \\
\hline 1 & $\mathrm{C}_{2} \mathrm{H}_{5} \mathrm{OH}$ & 20 & +13.8 \\
\hline 2 & 1,4-DOX & 20 & +13.3 \\
\hline 3 & $\left(\mathrm{CH}_{3}\right)_{2} \mathrm{SO}$ & 20 & +13.3 \\
\hline 4 & $\mathrm{C}_{2} \mathrm{H}_{5} \mathrm{OH} / \mathrm{LiCl}$ & 20 & +14.7 \\
\hline 5 & $n-\mathrm{C}_{4} \mathrm{H}_{9} \mathrm{OH}$ & 20 & +11.6 \\
\hline 6 & $n-\mathrm{C}_{4} \mathrm{H}_{9} \mathrm{OH}$ & $\sim 80$ & $\sim+11.4$ \\
\hline
\end{tabular}

a The polymer sample was prepared in tetrahydrofuran at $50^{\circ} \mathrm{C}$ (see Table I, No. 1).

Table IV. Asymmetric reduction of monomeric ketones and $1: 1$ copolymers via $\mathrm{Rh}$-catalyzed hydrosilylation ${ }^{\mathrm{a}}$

\begin{tabular}{|c|c|c|c|}
\hline $\begin{array}{l}\text { Reaction } \\
\text { product }\end{array}$ & $\begin{array}{c}\mathrm{CH}_{3} \\
\text { ' } \\
\left(\mathrm{CH}_{2}-\mathrm{C}\right)_{n} \\
\text { ' } \\
\mathrm{H}-\mathrm{C}^{*}-\mathrm{OH} \\
1 \\
\mathrm{CH}_{3} \\
+13.8\end{array}$ & $\begin{array}{c}\mathrm{CH}_{3} \\
1 \\
\mathrm{H}_{3} \mathrm{C}-\mathrm{C}-\mathrm{CH}_{3} \\
1 \\
\mathrm{H}-\mathrm{C}^{*}-\mathrm{OH} \\
1 \\
\mathrm{CH}_{3} \\
-2.7^{\mathrm{c}}\end{array}$ & 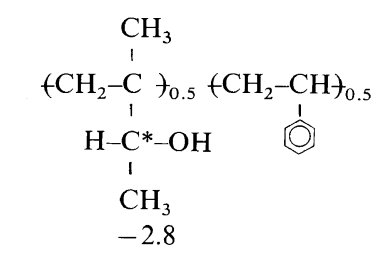 \\
\hline $\begin{array}{l}\text { Reaction } \\
\text { product }\end{array}$ & $\begin{array}{c}\left(\mathrm{CH}_{2}-\mathrm{CH}\right)_{n} \\
\stackrel{1}{\mathrm{C}}-\mathrm{OH} \\
\stackrel{\mathrm{H}}{*}-\mathrm{H} \\
\stackrel{\mathrm{C}}{\mathrm{C}} \mathrm{H}_{3}\end{array}$ & $\begin{array}{c}\mathrm{H}_{3} \mathrm{C}-\mathrm{C} \mathrm{H}-\mathrm{CH}_{3} \\
\text { ' } \\
\mathrm{H}-\mathrm{C}^{*}-\mathrm{OH} \\
\text { । } \\
\mathrm{CH}_{3}\end{array}$ & $\begin{array}{c}\left(\mathrm{CH}_{2}-\mathrm{CH}\right)_{0.5}+\mathrm{CH}_{2}-\mathrm{CH} \vartheta_{0.5} \\
\stackrel{1}{\mathrm{H}-\mathrm{C}^{*}-\mathrm{OH}} \\
\stackrel{1}{\mathrm{C}} \mathrm{H}_{3}\end{array}$ \\
\hline$[\alpha]_{\mathrm{D}}^{20} /^{\circ}$ & $+27.3^{\mathrm{b}}$ & $-1.0^{\mathrm{d}}$ & -7.9 \\
\hline
\end{tabular}

a Hydrosilylated at $50^{\circ} \mathrm{C}$ for 3 days in tetrahydrofuran: $[\mathrm{C}=\mathrm{O}]=0.50 \mathrm{~mol} \mathrm{dm}^{-3},[\mathrm{C}=\mathrm{O}] /[\mathrm{Rh}]=100,[\mathrm{Si}] /[\mathrm{C}=\mathrm{O}]=$ $1.5,[(-) \mathrm{DIOP}] /[\mathrm{Rh}]=1.0$.

b Data from ref 6 .

c Corresponds to an enantiomeric excess of $33.3 \%$ ( $\mathrm{R}$ form).

d Corresponds to an enantiomeric excess of $20.0 \%$ ( $R$ form). 
than that of the product from poly(isopropenyl methyl ketone) (see Table IV). This is contrary to expectation since steric effect should be more pronounced in poly(isopropenyl methyl ketone). A possible reason for this is the difference in steric structures of both polymers; poly(methyl vinyl ketone) and poly(isopropenyl methyl ketone) prepared by radical polymerization are atactic and mainly syndiotactic, respectively, according to ${ }^{13} \mathrm{C}$ NMR. ${ }^{14,15}$

In order to obtain more information about the asymmetric reduction of poly(isopropenyl methyl ketone) and poly(methyl vinyl ketone), the asymmetric reductions of monomeric ketones and $1: 1$ copolymers of either isopropenyl methyl ketone or methyl vinyl ketone with styrene were carried out under the same conditions (see Table IV). In contrast to poly(isopropenyl methyl ketone) and poly(methyl vinyl ketone), both pinacolone and isopropyl methyl ketone gave products having negative small optical rotations. The optical yields were $c a$. $20-30 \%$, which is reasonable as compared with the results for similar products in the literature. ${ }^{10}$ The products from 1:1 copolymers with styrene also showed negative small values.

In brief, the products from homopolymers of vinyl and isopropenyl ketones possessed positive large optical rotations, whereas all the products from monomeric ketones and copolymers had negative small values. A possible explanation for this is as follows: For the hydrosilylation of the homopolymers, acetyl groups in the adjacent monomer unit to the reacting acetyl group ligate the rhodium metal at the transition state, thus bringing about a unique and high asymmetric induction.

In conclusion, the asymmetric reduction of poly(isopropenyl methyl ketone) via $\mathrm{Rh}(\mathrm{I})$ catalyzed hydrosilylation provided a new polymer, poly(3-methyl-3-buten-2-ol), which exhibited a high optical rotation.

Acknowledgment. The authors express their gratitude to Professor T. Higashimura for his valuable suggestions and encouragement.

\section{REFERENCES}

1. For reviews, see (a) P. Pino, Adv. Polym. Sci., 4, 393 (1965); (b) T. Tsuruta, J. Polym. Sci., D, 6, 179 (1972).

2. J. W. ApSimon and R. P. Seguin, Tetrahedron, 35, 2797 (1979).

3. D. Valentine, Jr. and J. W. Scott, Synthesis, 329 (1978).

4. H. B. Kagan, Pure Appl. Chem., 43, 401 (1975).

5. T. Masuda and J. K. Stille, J. Am. Chem. Soc., 100, 268 (1978).

6. T. Masuda and H. Ibuki, Polym. J., 12, 143 (1980).

7. E. F. Landau and F. P. Irany, J. Org. Chem., 12, 422 (1947).

8. A. van der Ent and A. L. Onderdelinden, Inorg. Synth., 14, 92 (1973).

9. H. B. Kagan and T. P. Dang, J. Am. Chem. Soc., 94, 6429 (1972).

10. R. A. Benkeser, H. Landesman, and D. J. Foster, $J$. Am. Chem. Soc., 74, 648 (1952).

11. I. Ojima, K. Yamamoto, and M. Kumada, "Aspects of Homogeneous Catalysis," Vol. 3, R. Ugo, Ed., D. Reidel Publishers Co., Donarecht-Holland, 1977.

12. Y. Okamoto, K. Suzuki, K. Ohta, K. Hatada, and H. Yuki, J. Am. Chem. Soc., 101, 4763 (1979).

13. K. Takemoto and M. Miyata, J. Macromol. Sci., Rev. Macromol. Chem., C18, 83 (1980).

14. M. Kawai, T. Masuda, and T. Higashimura, unpublished data.

15. L. Merle-Aubry and Y. Merle, Eur. Polym. J., 16, 227 (1980). 